Objectives: The objective of this study was to evaluate the prevalence of hyperuricemia in PsA patients and to identify the associated factors.

Methods: Design: cross-sectional study, including consecutive, unselected, adult PsA patients. Data collection: demographic variables (age, gender, disease duration), clinical variables (affected joints, current moderate/severe psoriasis, nail disease, axial involvement, enthesitis, dactylitis), biological factors (acute phase reactants), treatment-related variables (non-steroidal antiinflamatory drugs, corticosteroids, synthetic and biologic disease modifying drugs) and comorbidities [2]. Hyperuricemia was defined as uric acid level above $6.8 \mathrm{mg} / \mathrm{dl}$ [3]. Statistical analysis: the factors that were potentially associated with hyperuricemia were assessed by Spearman correlation and uni- and multivariate logistic regressions. Results: In all, 120 PsA patients were included in the study: 69 (57.5\%) women, mean age \pm standard deviation $54 \pm 11.8$ years, mean disease duration $7 \pm 7.4$ years; $24(20 \%)$ had moderate/severe psoriasis and $30(25 \%)$ were taking a biologic. A high percentage of patients had cardiovascular comorbidities, i.e., dyslipidemia $80 \%$, hypertension $51.7 \%$, obesity $34.2 \%$ and cardiovascular events $34.2 \%$. Around a quarter of patients had hyperuricemia (33; $27.5 \%$ ). Hyperuricemia was significantly associated with obesity, diabetes, ischemic heart disease and hypertension, but there was no correlation with current skin psoriasis. In the multivariate analysis, it was best explained by diabetes (odds ratio: 4.95, [95\% confidence intervals: $1.47 ; 16.67])$, ischemic heart disease $(3.61[1.00 ; 12.98])$ and obesity $(1.86[1.04 ; 3.32])$.

Conclusions: Hyperuricemia in PsA is associated with metabolic syndrome rather than skin psoriasis, but further longitudinal studies are needed to identify causal relationships.

References:

[1] Bruce IN, Schentag CT, Gladman DD. Hyperuricemia in psoriatic arthritis: prevalence and associated features. J Clin Rheumatol 2000;6(1):6-9.

[2] Baillet A, Gossec L, Carmona L, et al. Points to consider for reporting, screening for and preventing selected comorbidities in chronic inflammatory rheumatic diseases in daily practice: a EULAR initiative. Ann Rheum Dis 2016;75(6):965-73.

[3] Campion EW, Glynn RJ, DeLabry LO. Asymptomatic hyperuricemia. Risks and consequences in the Normative Aging Study. Am J Med 1987;82(3):421-6.

Disclosure of Interest: None declared

DOI: 10.1136/annrheumdis-2017-eular.5744

\section{AB0791 HIGH PREVALENCE OF METABOLIC DISORDERS AND OBESITY IN PSORIATIC ARTHRITIS COMPARED TO PSORIASIS ALONE: A RETROSPECTIVE DERMATOLOGICAL CLINIC-BASED STUDY}

N. Batkaeva ${ }^{1}$, T. Korotaeva ${ }^{2}$, E. Batkaev ${ }^{1} .{ }^{1}$ Department of dermatology, RUDN University; ${ }^{2}$ V.A. Nasonova Research Institute of Rheumatology, Moscow,

Russian Federation

Background: An association between increased adiposity, obesity (Obs), and psoriasis has emerged. In addition to obesity, patients with psoriasis are more likely to have metabolic syndrome.

Objectives: to evaluate the prevalence of endocrine diseases, nutritional and metabolic disorder (ENMD) comorbidity in patients (pts) with PsA and Psoriasis (PsO) patients without arthritis in the dermatological hospital cohort.

Methods: 889 pts (Male-516/Female-329) with moderate-to-severy plaque PsO, mean age $50.4 \pm 17.6$ years, mean $\mathrm{PsO}$ duration $21.5 \pm 14.7$ were included. $\mathrm{PsO}$ pts with Endocrine, nutritional and metabolic diseases (E00-E90) (ENMD), including Disorders of thyroid gland (E00-E07), Obesity and other hyperalimentation (E65E68), Diabetes mellitus (E10-E14) (DM) were identify in the hospital Database reporting and coding by International Statistical Classification of Disease and Related Health Problems (ICD-10) between 2010 - 2015 years. M \pm m, t-test, $\chi^{2},(\%)$ were calculated. All $\mathrm{p}<0.05$ were considered to indicate statistical significance.

Results: 302 out of 889 pts (33.9\%) had PsA and 587 out of 889 pts $(66.1 \%)$ had $\mathrm{PsO}$ alone. PsA pts were older then $\mathrm{PsO}$ pts $-55.3 \pm 13.7$ and $50.4 \pm 17.6$ $(p<0.001) .155$ out of 889 pts $(17.4 \%)$ had ENMD. In PsA pts ENMD were found in significantly more cases than in $\mathrm{PsO}$ pts - in 76 out of 302 pts $(25.2 \%)$ and in 79 out of 587 pts $(13.5 \%)$ accordingly $\left(\chi^{2}=18.986, d f=2, p<0.00001\right)$. In PsA pts ENMD coding as E00-E07 were found in significantly more cases than in PsO pts - in 25 out of 302 pts (8.3\%) and in 23 out of 587 pts (3.9\%) accordingly $\left(x^{2}=7.4211, d f=2, p=0.00645\right)$. Obs coding as $E 65-E 68$ were found in significantly more cases in PsA pts compare to PsO pts - in 54 out of 302 pts $(17.9 \%)$ and in 64 out of 587 pts $(10.9 \%)$ accordingly $\left(\chi^{2}=8.4345, d f=2, p=0.00368\right)$.

DM coding as E10-E14 were found in more cases in PsA pts compare to PsO pts - in 54 out of 302 pts (17.9\%) and in 83 out of 587 pts $(14.1 \%)$ accordingly $\left(\chi^{2}=2.1410, d f=2, p=0.14341\right)$.

Conclusions: ENMD comorbidities are common for $\mathrm{PsA}$ and $\mathrm{PsO}$ without arthritis pts. Obs and disorders of thyroid gland were found in significantly more cases in PsA pts compare to PsO pts. Obesity and PsA are an unhealthy combination. Obesity may represent an additive cardio-metabolic risk factor in PsA subjects. High frequency of ENMD in PsA than PsO could be due to share inflammation pathways with insulin resistance and age. Patients with more severe psoriasis are at higher odds of endocrine, nutritional and metabolic diseases compared with those with mild psoriasis.

Disclosure of Interest: None declared
DOI: 10.1136/annrheumdis-2017-eular.2969

\section{AB0792 CURRENT STATUS AND UNMET NEEDS IN THE MANAGEMENT OF PSORIATIC ARTHRITIS WITH CONVENTIONAL SYNTHETIC AND BIOLOGICAL DISEASE MODIFYING ANTI-RHEUMATIC DRUGS: TAIWANESE NATIONWIDE PHYSICIANS' PERSPECTIVES}

T.-H. Li ${ }^{1}$, C.-C. Lai ${ }^{2}$, C.-Y.T. Tsai ${ }^{2} .{ }^{1}$ Division of Allergy, Immunology and Rheumatology, Department of Internal Medicine, Chiayi Branch, Taichung Veteran General Hospital, Chiayi City; ${ }^{2}$ Division of Allergy, Immunology and Rheumatology, Department of Internal Medicine, Taipei Veteran General Hospital, Taipei City, Taiwan, Province of China

Background: Psoriatic arthritis (PsA) contributes to enormous burden of disease and thus early correct diagnosis and adequate therapeutic management are essential for physicians in practice; however, There have been several studies highlighting the inadequate diagnosis and suboptimal therapies for PsA worldwide and physicians generally report difficulties in managing psoriasis.

Objectives: To analyze the real-world clinical practice of PsA in Taiwan, and assess physicians' adopted methods and difficulties of diagnosis, therapeutic consideration and strategy, in addition to rationales for biologic agents and unmet needs.

Methods: A nationwide cross-sectional observational study in Taiwan was conducted by means of the face-to-face in depth interviews with the 80 physicians, composed of 50 rheumatologists and 30 dermatologists, from November 2014 to January 2015.

Results: The major adopted diagnostic examinations for PsA are arthritis performance, psoriasis and nail dystrophy, roentgenological studies, personal and family history; however, more dermatologists rely on RF for initial diagnosis $(p<0.05)$. The difficulties for diagnosis, considerations on therapeutic management and current prescription were reported and displayed some interdisciplinary difference. Rationales for biological agent selection were investigated and physicians generally favored etanercept in terms of milder symptoms or more conservative treatment. The main unmet needs for current biologic therapies for PsA included the aspects of better efficacy, safety, sustainability and oral administration.

Conclusions: The nationwide study is the first survey for real-world clinical practice of PsA in Asia and provides detailed messages about the diagnostic difficulties and therapeutic consideration, especially rationales and unmet needs on current biologic therapies, which may offer possible directions for new drug development. We also made interdisciplinary comparison, hence in order to improve comprehensive care.

\section{References:}

[1] Liu JT, Yeh HM, Liu SY, Chen KT. Psoriatic arthritis: Epidemiology, diagnosis, and treatment. World J Orthop 2014;5:537-43.

[2] van de Kerkhof PC, Reich K, Kavanaugh A, et al. Physician perspectives in the management of psoriasis and psoriatic arthritis: results from the populationbased Multinational Assessment of Psoriasis and Psoriatic Arthritis survey. J Eur Acad Dermatol Venereol 2015;29:2002-10.

Disclosure of Interest: None declared

DOI: 10.1136/annrheumdis-2017-eular.1360

\section{AB0793 EFFICACY OF IXEKIZUMAB IMPROVING SF-36 SCORES IN BIOLOGIC DMARD-NAIVE PATIENTS WITH ACTIVE PSORIATIC ARTHRITIS: RESULTS FROM A PHASE 3 STUDY (SPIRIT-P1)}

V. Strand $^{1}$, A.B. Gottlieb ${ }^{2}$, T.K. Kvien ${ }^{3}$, A. Naegeli ${ }^{4}$, C.-Y. Lin ${ }^{4}$, O. Benichou ${ }^{4}$, J. Birt ${ }^{4} .{ }^{1}$ Stanford University School of Medicine, Palo Alto; ${ }^{2}$ New York Medical College, Valhalla, United States; ${ }^{3}$ Diakonhjemmet Hospital, Oslo, Norway; ${ }^{4}$ Eli Lilly and Company, Indianapolis, United States

Background: In a phase 3 randomized controlled trial (RCT), ixekizumab (IXE), a high affinity $\mathrm{mAb}$ that selectively targets interleukin-17A, significantly improved signs and symptoms of psoriatic arthritis (PSA)and health status vs placebo $(\mathrm{PBO})^{1}$.

Objectives: To evaluate the efficacy of IXE improving patient (pt)-reported health status, assessed by Short Form Survey (SF-36) physical and mental component summary (PCS and MCS) and domain scores in pts with active PSA vs PBO, compared with age-and gender (A/G)-matched population normative scores ${ }^{2}$.

Methods: In phase 3 RCT (SPIRIT-P1; NCT01695239), bDMARD-naive pts with active PSA $(\mathrm{N}=417)$ randomly received IXE $80 \mathrm{mg}$ either once every $4 \mathrm{Wks}(\mathrm{Q} 4 \mathrm{~W})$ or 2 Wks (Q2W) after a $160 \mathrm{mg}$ starting dose, or $40 \mathrm{mg}$ adalimumab (ADA) Q2W, or PBO (all subcutaneous). Health status was assessed by SF-36 at baseline, Wk 12, and Wk 24. Treatment comparisons were by mixed model for repeated measures for continuous data and logistic regression for categorical data. Missing values were imputed by nonresponder imputation.

Results: Baseline SF-36 scores were similar across treatment groups. At Wk 24 , significant improvements vs PBO were observed with ADA and IXEQ2W for PCS, and $5 / 8$ domains (PF, RP, BP, GH, and RE), and with IXEQ4W for PCS and 6/8 domains (except VT and MH) (Figure) (post hoc for individual domains). In pts with baseline scores $<\mathrm{A} / \mathrm{G}$ norms, significant improvements vs $\mathrm{PBO}$ were observed with ADA and IXEQ4W for PCS, MCS, and 5/8 domain scores (PF, RP, 